\title{
Systems that improve the behaviour of joints made using glued-in rods
}

\author{
D. Otero-Chans ${ }^{1}$, J. Estévez-Cimadevila ${ }^{1}$, E. Martín-Gutiérrez ${ }^{1}$, F. Suárez-Riestra ${ }^{1}$ \\ (1) University of A Coruña, Department of Architectural, Civil and Aeronautical Building Structures, \\ Campus A Zapateira, 15071, A Coruña, Spain. \\ Corresponding author: marilo@udc.es (Dolores Otero-Chans) \\ ORCID:https://orcid.org/0000-0003-1738-252X (Dolores Otero-Chans) \\ https://orcid.org/0000-0002-8460-2097 (Javier Estévez-Cimadevila) \\ https://orcid.org/0000-0001-7464-4288 (Emilio Martín-Gutiérrez) \\ https://orcid.org/0000-0002-8839-5611 (Félix Suárez-Riestra)
}

\begin{abstract}
Joints made using glued-in rods have been the subject of many numerical and experimental studies. The joints most widely used are those known as cylindrical joints, i.e., joints made using cylindrical rods of constant cross-section that are inserted into cylindrical holes that also have a constant cross-section. Although no agreement has been reached at a European level that would allow their dimensions to be included in structural standards, there is agreement in the literature on the fact that joint strength does not increase in a linear way with length. It has also been found that there is a maximum joint length above which its withdrawal strength does not increase. After reviewing the literature on the use of glued-in rods, this paper classifies the papers that describe different alternatives to cylindrical holes that have been suggested to improve joint behaviour. These alternatives modify the shape of the rods or the holes, or use additional elements. The paper also describes the results of a broad experimental campaign, which performed a comparative analysis of different types of glued-in rods based on modifying the shape of the hole to increase joint load capacity without the need to use long anchorages. Three different forms of improvement were studied, using several different anchorage lengths and wood species. The results show alternatives that improve strength by up to 60\% when compared with traditional joints and which can be used in different wood species at different slenderness values.
\end{abstract}

KEYWORDS: Glued-in rods, Timber structures, Joints. 


\section{Introduction: traditional system-only cylindrical holes}

Traditional joints made with glued-in rods (GiR) are composed of a rod that is inserted into a pre-drilled hole filled with structural adhesive in wooden structural elements (Fig. 1-0). Joints of this type are an option in the design of new structures as well as in the refurbishment or restoration of existing ones. Joints made with gluedin rods offer major advantages when used in wooden structures: they are able to transmit high tensile forces with limited deformation, making it possible to design extremely rigid joints; they can be designed for ductile failure when steel bars are used as connection elements; they have aesthetic advantages and also behave well in case of fire as the joint elements are concealed; these joints are light, as a large load can be transmitted by a small number of bars; they are versatile to execute, making it possible to use them in many types of structure and even in complex geometries; they can be prefabricated in a workshop using standard parts and are fast to install on site, etc.
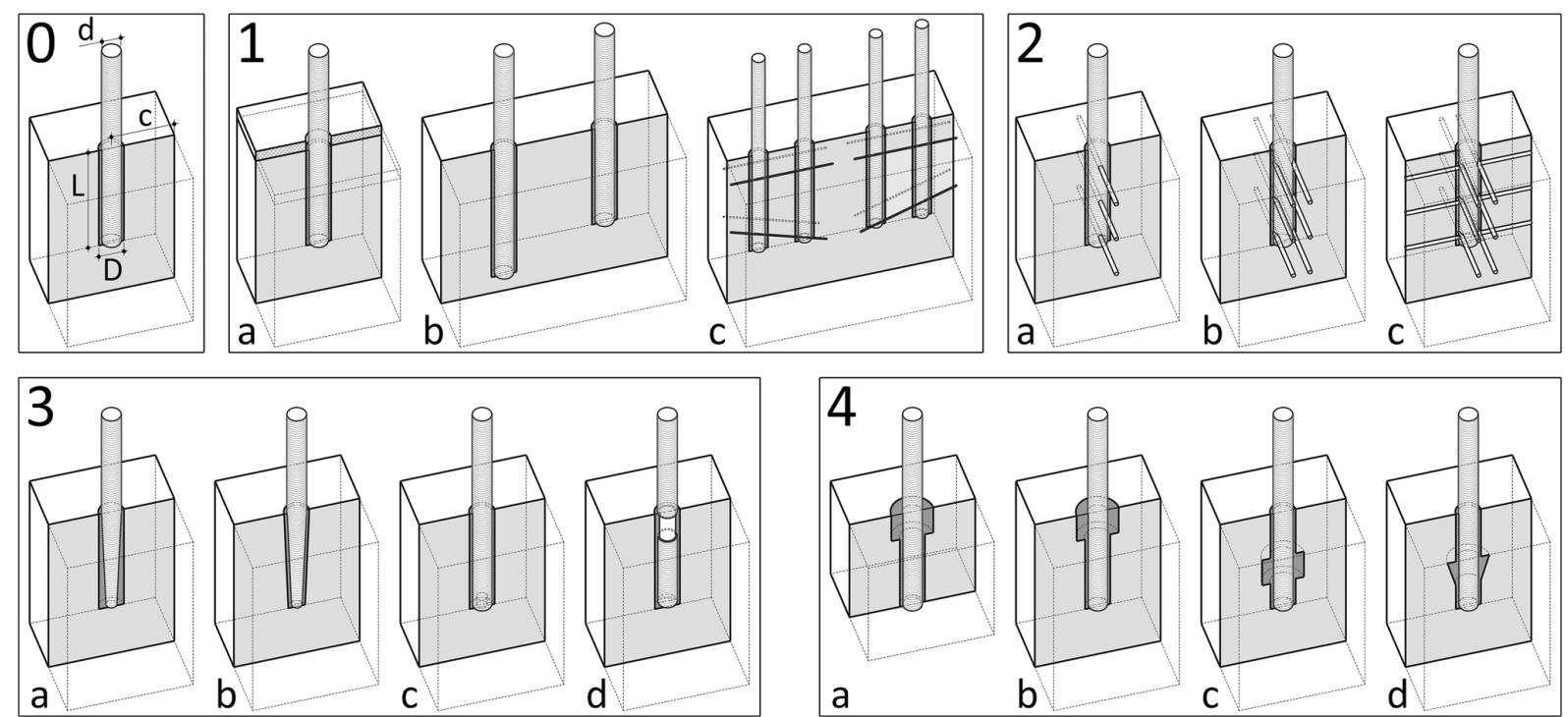

Fig. 1 Drawings showing the enhancements proposed in the literature (1-4) compared to the traditional cylindrical solution $(0)$

GiR were originally used as elements to counterbalance the problems of delamination and tension perpendicular to the fibre in curved, hollow or shaped laminated wood elements (Steiger et al. 2015). After the 1980s, they started to be studied to evaluate their behaviour in the design of joints in new constructions.

Studies have focussed on analysing the different parameters that influence joint strength. On the one hand, there are the material parameters: adhesive type, the type of rod and its surface treatment, as well as the characteristics of the wood. Although the first studies mainly used glued laminated spruce, analysis then broadened to include many other softwood and hardwood species; other types of products were also studied, mainly sawn, laminated veneer lumber and cross-laminated timber (Grunwald et al. 2019a; Hunger et al. 2016).

The effect of geometrical parameters on joint strength has also been studied, in particular the thickness of the adhesive layer, glued length and rod diameter. The relationship between the glued length and the rod diameter, through what is known as the slenderness of the joint ( $\lambda=\mathrm{L} / \mathrm{D}$, Fig. 1-O), has been found to be a fundamental 
parameter in their strength. Nevertheless, there is still no agreement at a European level on a size criterion, so that joints of this type are not covered by European wood structural design standards (Eurocodes). Only some countries such as Germany or Italy include this type of joint in their state standards. Spacing, end and edge distances of the rods are also key joint behaviour parameters. Minimum distances must be used to prevent failure due to splitting or other forms of premature failure in wooden pieces (Fig. 2a, b) (Steiger et al. 2015; Tlustochowicz et al. 2011).

Lastly, some authors studied the influence of another series of parameters on GiR strength, as they are factors, which affect the behaviour of the materials used in a joint, especially the wood and adhesive. These parameters are: their response to high temperatures or their behaviour in case of fire, the humidity content of wood, longterm loads, execution quality control and even test methodology, among others.

Several authors (Steiger et al. 2015; Tlustochowicz et al. 2011) have described the state of the art based on different studies of cylindrical anchorage joints of this type, as well as their conclusions on how different parameters affect their behaviour. They even undertook comparative analysis of the results of some of the proposed designs, according to their dimensions. More recently, Grunwald et al. (2019b) evaluated the different models used for GiR strength prediction.

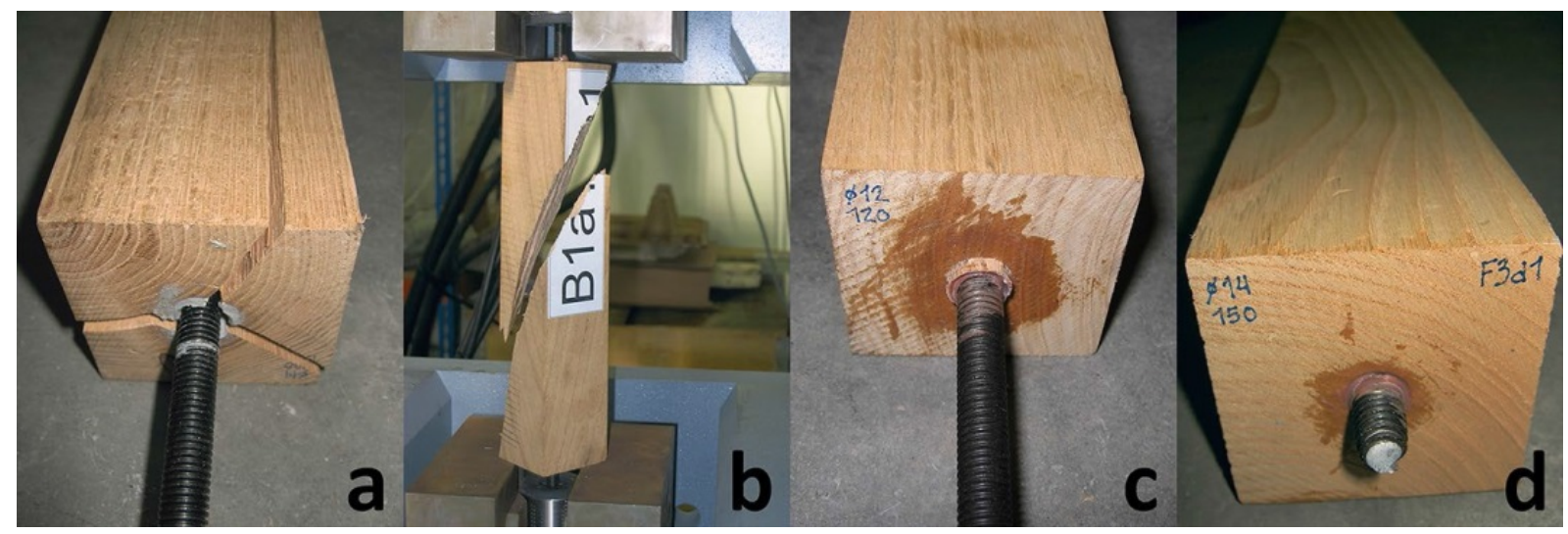

Fig. 2 Common failure modes in traditional GiR. a Splitting failure in timber; b tensile failure in timber; $c$ shear failure in timber-adhesive interface; $d$ tensile failure in rod

Different authors agree on one key aspect in the behaviour of joints. This is that their strength varies depending on the wood/adhesive interface, on condition that the aforementioned minimum distances are complied with (spacing, end and edge distance) as these may cause premature failure in the wood prior to failure of the joint. This surface is generally where joints fail, and it is usually associated with failure due to wood shearing (Fig. 2c). To prevent this brittle type of failure, it is recommended that failure be made conditional on breakage due to rod tension (Fig. 2d), which is only possible for steel rods. This criterion means that the shear resistance of the wood/adhesive interface must be known beforehand. This is the magnitude that a range of proposed design expressions have tried to quantify. The authors agree that although the strength of a joint varies with the wood/adhesive interface, this relationship is not linear. Among other factors, this is due to the fact that stresses are distributed along a joint in a non-homogeneous way, with peaks at its ends. The size of these peaks is affected by the rigidity of the materials as well as the slenderness of the joint. This phenomenon has traditionally been used to determine joint strength. Authors such as Grunwald et al. (2019b) suggest a 
probabilistic approach to determine joint strength that goes beyond this consideration of maximum local tensions. They consider the transverse tensile strength of the wood to be at least as important as shear strength in joint capacity. It is widely accepted that longer joints fail at lower average stresses. This aspect is expressed by the fact that for a certain rod diameter, there is a glued length above which length increases hardly lead to increased joint load-bearing capacity (Muciaccia 2019; Steiger et al. 2015; Tlustochowicz et al. 2011; Vallée et al. 2017).

Due to this limitation, over the years different authors have proposed alternatives to traditional cylindrical anchorages, i.e., a cylindrical rod inserted into a wider cylindrical hole (Fig. 1), in an attempt to improve the behaviour of GiR. The second section of this paper reviews the literature, describing the main proposals for improvement in this field and the results obtained.

Additionally, the Architectural Structures Group (GEA, Division Timber GEM) from A Coruña University undertook extensive preliminary work with more than 700 trials of GiR cylindrical anchorage joints in different timber species. The results showed that the average density of the timber species used is also a decisive factor in the strength of joints, just as it is in the strength grading of timber as a structural material. Nevertheless, this relationship between density and joint strength is not linear. On the other hand, due to the variation in the modulus of elasticity between different species of timber, the effect of geometrical parameters on the strength of cylindrical joints with GiR is also affected by this timber characteristic. In all of the timber species tested, laminated as well as sawn, the average shear stress of joints fell as the slenderness (the ratio between the glued length and diameter) of the joint increased. However, in denser species this fall occurred at somewhat greater degrees of slenderness (Martín et al. 2013; Otero-Chans et al. 2008).

Preliminary studies showed that it is possible to obtain higher degrees of joint strength by using higher density timber. Grunwald et al. (2019a) and other authors compared the behaviour of GiR in different wood species or with different engineering wood products. They concluded that increased wood density does not always lead to increased joint capacity. In any case, and regardless of timber density, if cylindrical anchorages parallel to the fibre are used, at high levels of slenderness there is a length above which it is no longer possible to increase the load-bearing strength of joints due to the high stress peaks that arise in the ends, causing them to fail. These peaks in stress depend on the geometry of the joint and the rigidity of its elements. They tend to be highest in the interior end for short joints, and they increase in the exterior end as joint length increases (Otero-Chans et al. 2010, 2013).

These results led us to explore joint configuration alternatives that would make it possible to increase the strength of GiR without increasing their glued-in length, as described in Sect. 3 of this paper.

\section{Improved systems: a review of the literature}

The suggested ways of improving the behaviour of cylindrical anchorage GiR may be divided into four main groups: (1) hooped systems, (2) hybrid joints, which are known as such because they combine an adhesive joint with mechanical systems, (3) modified rod shapes and (4) modifications in the shape of the drilled hole. 


\subsection{Hoop-based improvement systems}

Hoop-based enhancement systems generally have the aim of preventing failure due to splitting of the wood (Fig. 2a). Failures of this type are chiefly associated with the use of small cross-sections that give rise to small distances from the edge. Different authors recommend the use of distances between the centre of the hole and the edge of the piece from 2.5 to 5.0 times the diameter of the rod (Muciaccia 2019). When smaller sizes or sets of rods are used, failure may occur due to splitting caused by the transversal stresses originating in the joint. These methods of enhancement therefore do not increase joint strength, but rather make it possible to use the bearing strength of the rods without premature failure due to splitting.

In his pioneering studies, Riberholt (1986) tested joints that were reinforced by gluing birch plywood boards onto the end of the fibre to prevent the test pieces from splitting (Fig. 1-1a). Using reinforcing plates leads to test pieces failing due to tension instead of splitting, giving rise to an increase of around $15 \%$ in the failure load in comparison with unreinforced test pieces. Failure in the latter is mainly due to splitting of the wood, as test pieces were used with very short distances to the edge (about 1.5 times the diameter of the rod). Some test pieces were subjected to impregnation processes to evaluate the sensitivity of the joint to the humidity content of the wood. In these cases the efficacy of the reinforcement was reduced because the board was glued on using PVA adhesive.

In the case of multiple joints using sets of rods it is necessary to consider the possible effects of interaction between them, as they may give rise to poorer performance than would be the case for the sum of all the rods working individually. This aspect was experimentally corroborated by studies such as those by Gattesco and Gubana (2001), who tested multiple joints under tension (with two rods at each end) as well as simple joints. The results of extraction tests with two rods showed that they were made less effective by their mutual interaction; i.e., the load at which failure of joints with two rods occurred was found to be lower than twice the ultimate load with a single rod. This interaction is highly significant, especially with short distances between the rods and edge, because the wood splits, thereby determining the failure mechanism.

Sets of rods may also cause stresses to build up at the end of the block, leading to failure due to tension in the wooden element (Fig. 3a). Korin et al. (1999) performed tests with sets of four epoxy-glued rods and wood cross- sections that were four times larger than the cross-section used in standard tests of single rods. The maximum load obtained for the sets of rods corresponded to approximately $80 \%$ of four times the strength of a single rod. Respecting the arrangement of sets of rods, in multiple joints it is possible for failure to occur due to tension in the section of wood next to the end of the rods. Because of this the same authors suggest that the rod ends be staggered (varying their glued lengths) to prevent stresses concentrating at the end of the set (Fig. 1-1b). Nevertheless, test results showed no significant increases in strength when the rod ends were staggered in comparison with the flat solution (in which all of the rods are the same length).

Buchanan and Moss (1999) also suggested that the rods be staggered when they are arranged in different layers. These authors recommend that for bent sections the shortest rods should be towards the outside (Fig. 3c) instead of towards the inside (Fig. 3b), even though in this arrangement the longest rods are not in the areas under the greatest tension forces. They state that although their proposal has not been 
experimentally verified, it will lead to a lower probability of failure if a shrinkage crack appears in the end of the beam.

Gaunt (1999) evaluated the behaviour of sets of glued rods in the end of a beam arranged to transmit a bending moment. Preliminary trials showed faults arose due to the separation of the block that transmits the traction forces (Fig. 3b, c). To improve joint behaviour, it was proposed that lag screws or glued rods transversal and sloped respecting the longitudinal rods be used (Fig. 1-1c).
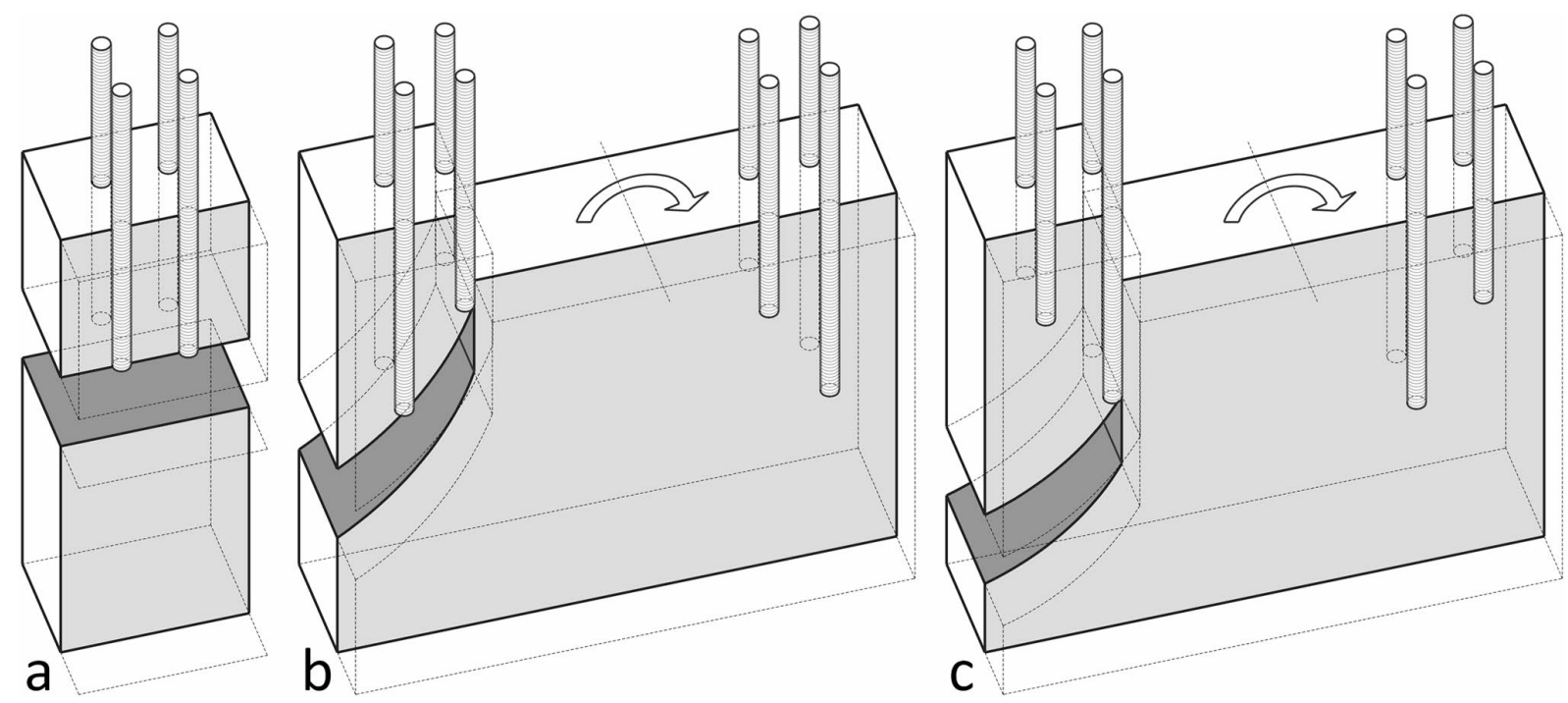

Fig. 3 Failure modes in GiR with multiple rods. a Tensile failure in timber at the end of the block of bars. b Block failure in an arrangement with staggered rods, where the longest rods are arranged towards the exterior of the section. $\mathrm{c}$ Block failure in an arrangement with staggered rods, where the longest rods are arranged towards the interior of the section

\subsection{Improvement systems based on hybrid connections}

These enhancement systems combine the adhesive joint with the mechanical work of transversal elements. This approach is half-way between a traditional mechanical joint and an adhesive solution. Due to the difference in rigidity, it is not possible to simply add the capacities of both solutions, although the mechanical joint functions more as a back-up to guarantee ductile failure if the adhesive joint fails. Additionally, these solutions complicate execution and lose their aesthetic advantage in comparison with hidden glued joints.

Buchanan et al. (2000) proposed using cement grout instead of adhesives to improve the behaviour of GiR joints in case of fire, because of the possible decrease in the adherence of some adhesives when they are subjected to high temperatures. The limitation which arises from using cement grout instead of adhesives lies in its lower, or zero, adherence to wood. These authors propose the use of transversal elements, dowels and screws, to mechanically strengthen joints with the aim of making them highly fire-resistant. The dowels are located in holes that run through the steel rod (Fig. 1-2a, 2b) and the screws pass through the wood and cement grout next to the rod (Fig. 1-2c). Additionally, the type of failure associated with this solution is ductile due to the bending of the transversal elements. This paper centred on evaluating strength rather than rigidity, which is usually far less in mechanical joints than it is in glued ones; i.e., the transmission of forces is associated with greater sliding of the rod and therefore with less rigidity in the joint as a whole. In this case, the rod does not 
necessarily have to be threaded or have projections, given that the mechanical work is done by the transversal elements.

These systems improve the ductility and degree of security of joints, reducing possible concentrations of stresses due to adhesive transmission of forces between materials; however, in comparison with systems that use a single glued rod, the joints they form are more difficult to produce, and they also lack their aesthetic advantages.

There is a commercial version based on this solution denominated the BertscheVerpress-Dübel, BVD System (BVD-Bertsche 1998; Aicher et al. 2012). Joints of this type use a cast steel element and include dowels and pins, which anchor the main steel rod transversally (Fig. 1-2c). In this case, cement grout is used to fill the gaps between the holes in the central steel rod and the transversal dowels. These gaps are necessary due to execution and assembly tolerances, and the cement grout ensures immediate contact between the rod and the dowel during the process of loading the joint, without any of the initial sliding associated with mechanical joints. Given that this is the sole function of the cement grout here, the joint is commercialised as mechanical rather than one that is glued or hybrid.

\subsection{Improvement systems based on modification of the rod shape}

Enhancement systems based on modifying the shape of the rod are based on the peaks of shear stress detected at joint ends. The magnitude of the peaks depends on the rigidity of the materials used and the geometrical proportions of the joint. Previous studies indicate that joint slenderness has a greater effect on stress distribution than variation in the rigidity of the adhesive or wood. The magnitude of extreme peaks tends to become uniform in shorter joints, while in more slender joints the greatest peaks occur in the exterior end of the joint (Otero-Chans et al. 2010; Vallée et al. 2017).

The pioneering studies by Riberholt and Spøer (1983) covered variations in rod geometry, with solid, hollow and conical designs. They proposed using pointed rods that are hollow in the interior end (Fig. 1-3a). Uhre Pedersen et al. (1999) discovered that a pointed hollow shape in the rod had a levelling effect on peak stress. Batchelar and McIntosh (1998) also recommended pointed rod ends to reduce stress concentrations (Harvey and Ansell 2000).

Korin et al. (1999) also carried out tests using conical rods, sharpening their interior end at an angle of 1:10 to reduce the concentration of stresses at this point. They added projections to the conical part of the rods to keep the mechanical transmission effect of threaded rods. They also constructed special drill bits to make conical holes in the interior pointed end of rods (Fig. 1-3b). They compared the results with the conventional solution (cylindrical-ended rods). For the dimensions they tested, the rods with pointed ends were not significantly stronger than those with cylindrical ends. Nevertheless, there was a difference in their failure modes. The most common type of failure for the test pieces with cylindrical-ended rods was fragile fracture of the wood due to tension in the section corresponding to the embedded end of the rod. When the rod end was pointed, the predominant failure mode changed to wood splitting or failure due to rod withdrawal, suggesting that the concentration of stresses in the rod ends had fallen. These authors presuppose that if the embedded length of these rods had been greater, there would have been a far larger strength increase with pointed rod ends. When the rod is pointed, it also has to be machined after being cut, to continue ensuring the mechanical transmission of forces. 
Wernersson and Gustafsson (1996) studied the behaviour of steel plates instead of rods glued on wood. They compared the behaviour of straight and tapered section plates experimentally and numerically. Numerically they assumed that tapering the plates could improve strength by 11-25\%, depending on the geometries studied. However, their experimental results with joints showed behaviour similar to what was expected, with less than 10\% increase. These results were obtained from a small number of tests.

Deng et al. (1998) studied stress distribution according to several parameters in a finite element model. One variation included drilling an $18 \mathrm{~mm}$ hole in the interior end of the threaded $20 \mathrm{~mm}$ diameter rods, to evaluate the possible fall in stress associated with a reduction in the rigidity of the rod at this point (Fig. 1-3c). The results of the model showed that shear stresses at this point fell by $50 \%$ in the drilled rods, which led the authors to conclude that stress concentration in the adhesive may be reduced by modifying the shape of the rod. The tensile stress along the wood and the transversal stresses do not seem to be affected by the change in shape of the end of the rod.

Steiger et al. (2004) proposed changing the shape of the exterior end of the rod instead of the interior end. They reduced the cross-section width of the rods by a certain length, machining them to eliminate the protrusions corresponding to the thread (Fig. 1-3d). By doing this, they aimed to reduce stress concentrations and prevent local splitting failures due to shear forces and stress perpendicular to the fibre, displacing the anchorage zone towards the interior. Although the entire hole is filled with adhesive (the machined zone as well as the part corresponding to the rest of the rod), the authors did not consider the contribution of the machined area, due to the loss of mechanical connection between the rod and the adhesive in this zone. They suggest that this may also be a suitable design for failure to occur in the steel rather than in the wood or adhesive, with the aim of achieving a ductile failure instead of a brittle one. In any case, in the tests performed, the joint failed in the majority of cases due to failure of the wood, given that high strength rods were used to evaluate the strength of the wood/adhesive bond. No comparative tests were performed without machining the rod that would have made it possible to evaluate the enhancement in strength obtained with this system.

\subsection{Improvement systems based on modifying the shape of the hole}

Fewer enhancement systems have been based on changing the shape of the hole to reduce peaks in stress that originate in the ends of joints because of the non-uniform distribution of stress described in the above section. Broughton and Hutchinson (2001) tested single-ended pull-through joints and compared them with doubleended pure tensile specimens. In some of the single-ended test pieces, they created a stepped counter-bored end close to the load, to reduce adhesive thickness from 6 to 2 mm (Fig. 1-4a). The glued length was $60 \mathrm{~mm}$, and they created different depths of countersinking. They concluded that peaks in stress would fall for lengths of countersinking greater than $30 \mathrm{~mm}$, and that beyond this size behaviour was similar to using a constant adhesive thickness of $6 \mathrm{~mm}$. They performed tests with through rods (Fig. 1-4a) instead of rods inserted in blind holes (Fig. 1-4b), and this may affect the stresses originating in the internal end.

There was another proposal for enhancement based on modifying the hole, although in this case it did not aim to reduce stress peaks along the joint. The objective in this case was to increase the mechanical work of the joint because it used cement grout 
with low adhesive power. When searching for alternatives to make it possible to use cement grout instead of adhesives, Buchanan et al. (2000) explored the use of keys in the form of holes to improve the adherence of cement grout to wood. They created a straight solution (Fig. 1-4c) as well as a tapered key solution (Fig. 1-4d), the latter in two different lengths. They concluded that the use of distinct keys made it possible to achieve slight increases in strength. These increases basically occur in the case of longer tapered keys. The type of failure, which occurred, is firstly due to crushing of the timber, followed by failure of the cement grout and the adhesive failure of this with the wood.

\section{Improvement systems: experimental study of solutions based on modifying the shape of the hole}

This section describes the different proposals used in the authors' group to improve the strength of GiR, as well as the limitations and enhancements corresponding to each one of the same.

All of the proposals studied, which are described below, involved solutions that modified the shape of the hole and used threaded $12 \mathrm{~mm}$ diameter rods glued using two-component epoxy adhesive. The cylindrical pre-drilled hole was $14 \mathrm{~mm}$ in diameter, with an adhesive thickness of at least $1 \mathrm{~mm}$. Different glued lengths were studied, as were different timber species and even, in some cases, different orientations respecting fibre direction; more than 800 joints were tested. All of the results of the proposed enhancements were compared with cylindrical anchorage joints using the same length, timber and orientation (Fig. 4-0).
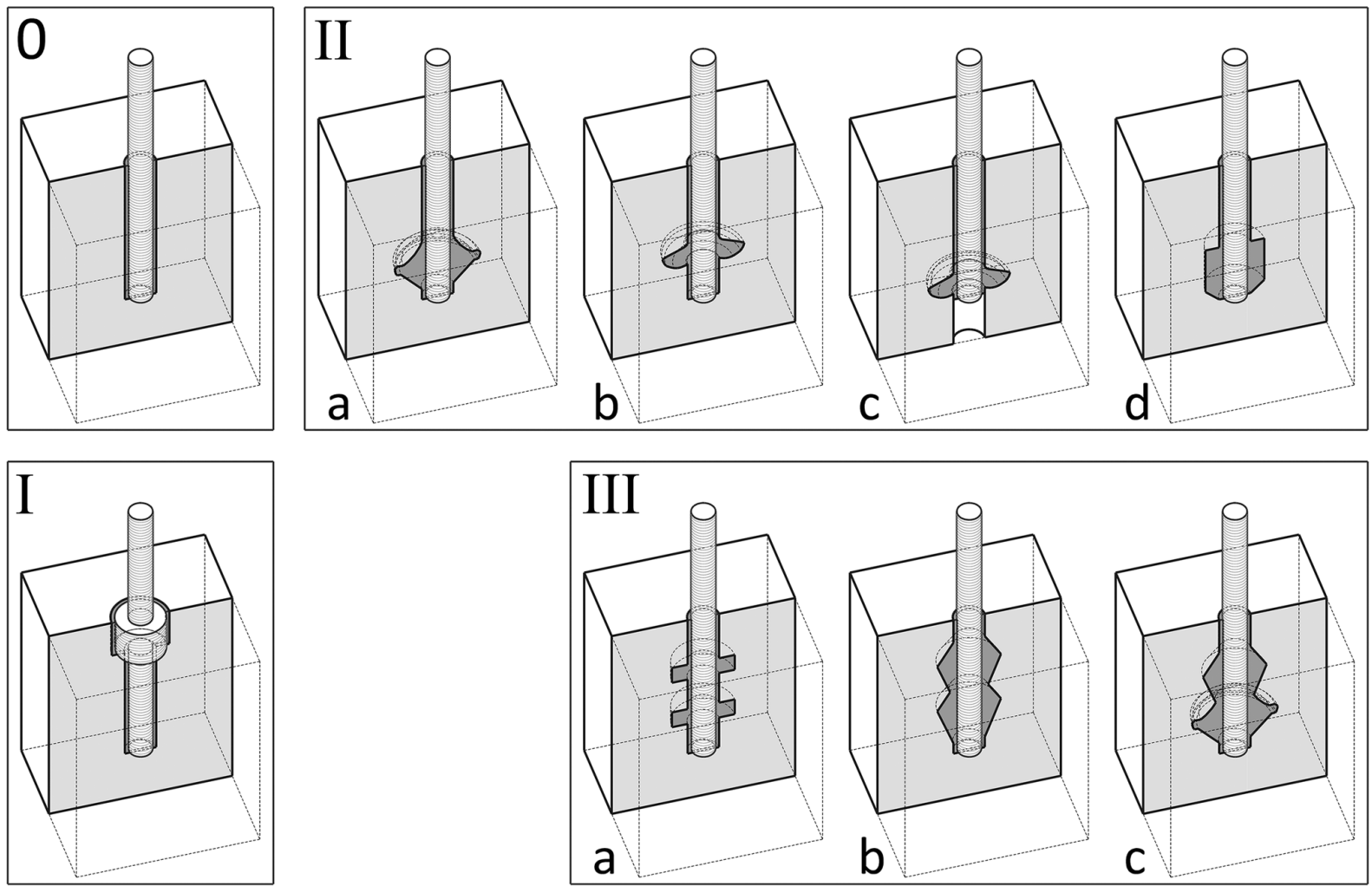

Fig. 4 Drawings of proposed enhancements studied experimentally (I-III) vs the cylindrical traditional solution (o) 
Table 1 shows experimental results for the different types of specimens tested. For each type of specimen and each anchorage length, the number of replicates tested, the average failure load and the standard deviation are shown. The results for each specimen type are described in the following sub-sections.

\subsection{Experimental analysis of the joints with external countersinking}

The first option studied involved making a countersink in the exterior end of the hole, similar to the proposal described in Sect. 2.4. In this case, an internally and externally threaded cylinder was used, with an external diameter of $26 \mathrm{~mm}$, with the aim of maintaining a uniformly thick layer of adhesive (Figs. 4-I, 5). The countersinking was $28 \mathrm{~mm}$ in diameter and $20 \mathrm{~mm}$ deep.

Table 1 Average failure load in $\mathrm{kN}$ (and standard deviation in brackets) for each type of specimen tested

\begin{tabular}{|c|c|c|c|c|c|c|c|c|}
\hline \multirow{2}{*}{$\begin{array}{l}\text { Anchora- } \\
\text { ge type }\end{array}$} & \multirow{2}{*}{ Timber species } & \multirow{2}{*}{$\begin{array}{c}\text { Specimen } \\
\text { type }\end{array}$} & \multirow[t]{2}{*}{$\mathrm{N}$} & \multicolumn{5}{|c|}{ Anchorage/glued length (L) and slenderness $(\lambda)$} \\
\hline & & & & $\begin{array}{c}\mathrm{L}=60 \mathrm{~mm} \\
\lambda=5.0\end{array}$ & $\begin{array}{c}\mathrm{L}=90 \mathrm{~mm} \\
\lambda=7.5\end{array}$ & $\begin{array}{c}\mathrm{L}=120 \mathrm{~mm} \\
\lambda=10.0\end{array}$ & $\begin{array}{c}\mathrm{L}=150 \mathrm{~mm} \\
\lambda=12.5\end{array}$ & $\begin{array}{c}\mathrm{L}=180 \mathrm{~mm} \\
\lambda=15.0\end{array}$ \\
\hline Type o & Spruce & II & 14 & $23.1(2.4)$ & $31.8(4.2)$ & $44.9(8.5)$ & $54.2(6.6)$ & $51.4(6.3)$ \\
\hline \multirow{6}{*}{$\begin{array}{l}\text { Cylindric } \\
\text { al holes }\end{array}$} & & $\perp$ & 12 & $17.0(1.8)$ & $24.5(2.6)$ & $37.9(3.7)$ & $47.3(3.4)$ & $52.9(2.6)$ \\
\hline & LVL & II & 14 & $18.6(1.9)$ & $28.3(2.8)$ & $34.4(2.0)$ & 43.7 (2.6) & $45.0(4.3)$ \\
\hline & & $\perp$ & 12 & $15.1(2.0)$ & $23.5(2.9)$ & $31.1(3.8)$ & $38.7(1.8)$ & $52.6(1.1)$ \\
\hline & Chestnut & $\|$ & 14 & $26.3(3.5)$ & $35.9(3.6)$ & $53.7(6.4)$ & $58.3(7.9)$ & $61.7(5.4)$ \\
\hline & Oak & II & 14 & - & $45.6(7.2)$ & $53.3(10.3)$ & $60.4(5.5)$ & $64.4(11.8)$ \\
\hline & Eucalyptus & II & 14 & - & $46.1(7.8)$ & $59.1(7.2)$ & $63.3(8.0)$ & $70.0(7.6)$ \\
\hline Type I & Spruce & $\|$ & 14 & $27.9(2.9)$ & $40.7(3.5)$ & $49.9(3.8)$ & - & - \\
\hline \multirow[t]{2}{*}{ Countersi } & & $\perp$ & 8 & - & - & - & $51.8(5.1)$ & $51.6(2.5)$ \\
\hline & LVL & $\perp$ & 8 & - & - & - & $39.4(2.1)$ & $53.9(3.3)$ \\
\hline \multirow{18}{*}{$\begin{array}{l}\text { Type II } \\
\text { Bulbs }\end{array}$} & Spruce II & Type IIa & 14 & $30.4(2.3)$ & $37.1(2.8)$ & $45.0(4.8)$ & - & - \\
\hline & & Type IIb & 7 & $27.6(4.6)$ & $35.6(3.7)$ & $45.6(2.2)$ & - & - \\
\hline & & Type IIc & 7 & $23.7(4.3)$ & $34.9(3.5)$ & $42.5(4.2)$ & - & - \\
\hline & & Type IId & 14 & $29.1(2.5)$ & $37.9(3.7)$ & $45.8(6.0)$ & - & - \\
\hline & Spruce $\perp$ & Type IIa & 12 & $20.5(3.9)$ & $28.6(2.8)$ & $41.4(2.6)$ & - & - \\
\hline & & Type IIb & 12 & $21.2(2.3)$ & $29.2(2.1)$ & $41.0(3.8)$ & - & - \\
\hline & & Type IId & 12 & $22.8(2.5)$ & $29.3(1.8)$ & $43.3(3.7)$ & - & - \\
\hline & LVL \| & Type IIa & 16 & $31.2(3.5)$ & $37.9(4.3)$ & $44.2(3.2)$ & - & - \\
\hline & & Type IId & 16 & $26.3(2.1)$ & 33.8 (2.9) & $43.5(2.8)$ & - & - \\
\hline & $\mathrm{LVL} \perp$ & Type IIa & 12 & 22.3 (1.9) & $33.3(3.1)$ & $41.0(3.5)$ & - & - \\
\hline & & Type IIb & 12 & $18.4(2.0)$ & $28.5(2.1)$ & $36.4(3.1)$ & - & - \\
\hline & & Type IId & 12 & $20.9(2.8)$ & $30.9(3.0)$ & $36.9(3.4)$ & - & - \\
\hline & Chestnut I| & Type IIa & 16 & $37.3(4.7)$ & $41.3(4.0)$ & $43.8(7.6)$ & - & - \\
\hline & & Type IId & 16 & $31.0(2.1)$ & $42.7(5.3)$ & $48.7(6.7)$ & - & - \\
\hline & Oak || & Type IIa & 16 & $39.8(5.8)$ & $49.5(5.1)$ & $51.2(7.5)$ & - & - \\
\hline & & Type IId & 16 & $40.1(4.4)$ & 52. (5.4) & 64.7 (6.9) & - & - \\
\hline & Eucalyptus II & Type IIa & 16 & $43.3(2.3)$ & 48.8 (6.9) & $60.1(5.5)$ & - & - \\
\hline & & Type IId & 16 & $39.3(3.8)$ & $56.0(5.5)$ & $69.2(7.6)$ & - & - \\
\hline \multirow{4}{*}{$\begin{array}{l}\text { Type III } \\
\text { Multi- }\end{array}$} & Spruce $\|$ & Type IIIb & 6 & - & $49.6(4.2)$ & $63.9(3.9)$ & 75.37 (7.97) & - \\
\hline & & Type IIIc & 6 & - & $41.9(4.1)$ & $56.4(8.1)$ & $72.83(5.11)$ & - \\
\hline & Chestnut II & Type IIIb & 6 & - & $59.7(5.3)$ & $75.3(5.4)$ & $91.1(5.07)$ & - \\
\hline & & Type IIIc & 6 & - & $51.0(3.8)$ & $66.4(3.5)$ & $80.45(5.12)$ & - \\
\hline
\end{tabular}

The number of replicates for each type of specimen is also shown

$\mathrm{N}$ number of specimens tested for each type and each anchorage length, $\lambda$ slenderness of the joint (L/D), || parallel to the grain, $\perp$ perpendicular to the grain 
Test pieces were made of glued laminated spruce timber (glulam) (with an average density of $430 \mathrm{~kg} / \mathrm{m} 3$ ) and laminated veneer lumber (LVL-Kerto-S with an average density of $530 \mathrm{~kg} / \mathrm{m} 3$ ). The glulam test pieces were glued parallel to the fibre over lengths of 60,90 and $120 \mathrm{~mm}$ (slenderness ratios, $\lambda$, of 5.0, 7.5 and 10.0) or were glued perpendicular to the fibre over lengths of 150 and $180 \mathrm{~mm}$ (slenderness ratios of 12.5 and 15.0). LVL test pieces were also tested, with glued joints perpendicular to the fibre, in the same sizes as the glulam pieces.

In the case of the hole drilled in spruce glulam test pieces, with slenderness ratios from 5 to 10, the average improvement achieved with countersinking in comparison with the cylindrical holes was similar in all three lengths studied, and it varied from 11.1 to $28.0 \%$ (Fig. 6).

Nevertheless, the enhancements achieved in the case of joints perpendicular to the fibre were not very significant. In spruce glulam joints, for a length of $150 \mathrm{~mm}$ the average enhancement only amounted to $9.5 \%$, while in the case of $180 \mathrm{~mm}$ long joints the countersunk test pieces were even found to be $2.5 \%$ less resistant than those with a cylindrical hole. The improvement in the LVL test pieces was $1.8 \%$ and $2.5 \%$ for the 150 and $180 \mathrm{~mm}$ lengths, respectively (Fig. 6).

This difference in the results may be due to the different stress distributions in the joint when anchorages paral lel and perpendicular to the fibre are used (Yeboah et al. 2016; Otero-Chans et al. 2014). Timber is far less rigid perpendicular to the fibre, giving rise to a more uniform stress distribution that in turn leads to an almost linear relationship between the load-bearing capacity and glued length, which is contrary to what has been described for joints made parallel to the fibre. Crack propagation and therefore failure modes also differ depending on the fibre orientation of the load (Grunwald et al. 2019b).

\subsection{Experimental analysis of joints with an internal bulb}

The second improvement system proposed is based on using wider sections or "bulbs" created in the interior end of the hole. This solution has two aims: on the one hand, the bulb has the purpose of reducing the peak stresses that arise at this point, while on the other hand, the shape of the hole will affect a larger block of wood, as it will also resist extraction of the bulb from the interior end. In this way, as well as the shear resistance of the wood/adhesive contact surface in a cylindrical hole, the bulb will exert compression from the interior of the piece on the surrounding wood (favouring the mechanical transfer of the load).

The implementation of this solution may be hindered by the difficulty in finding a tool that opens within the hole to create the bulb, without generating perpendicular tensile forces that would lead to failure due to splitting. Although the simplest solution may be to use an eccentric bit, the said eccentricity may give rise to problems with bit bending in long holes. This authors' team worked on the development and patenting of different bit types based on a set of articulated rods that open as the bit is inserted into a cylindrical pre-drilled hole. Different connecting rod geometries and arrangements make it possible to create bulbs in a variety of shapes (EstévezCimadevila et al. 2012). 


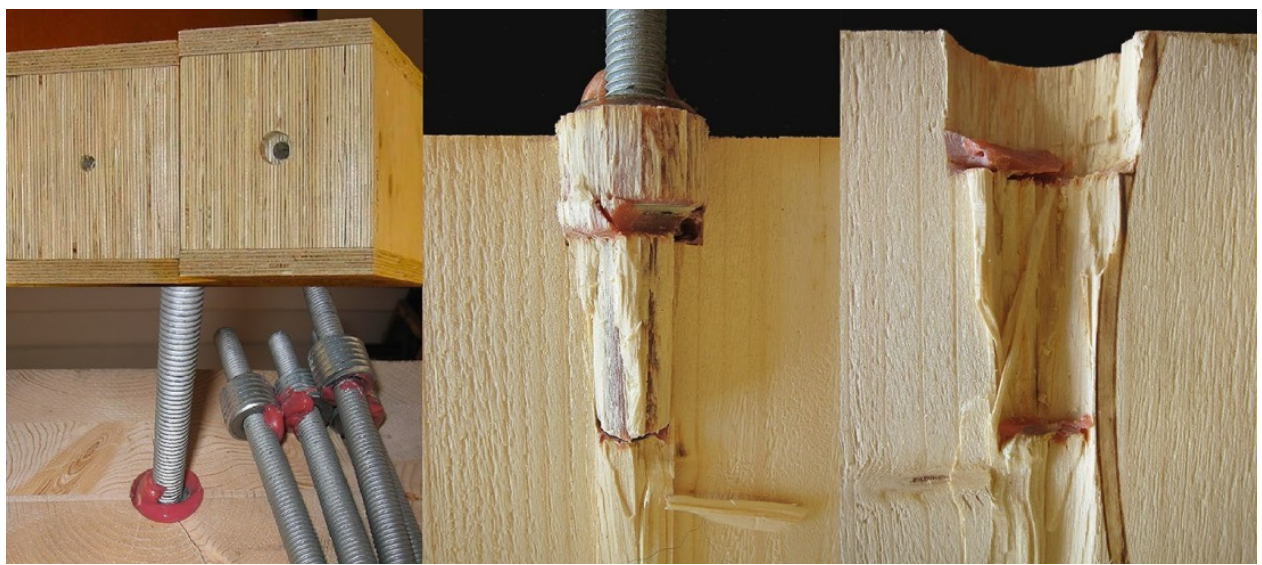

Fig. 5 Preparation of the specimens with exterior countersinking, and failure mode

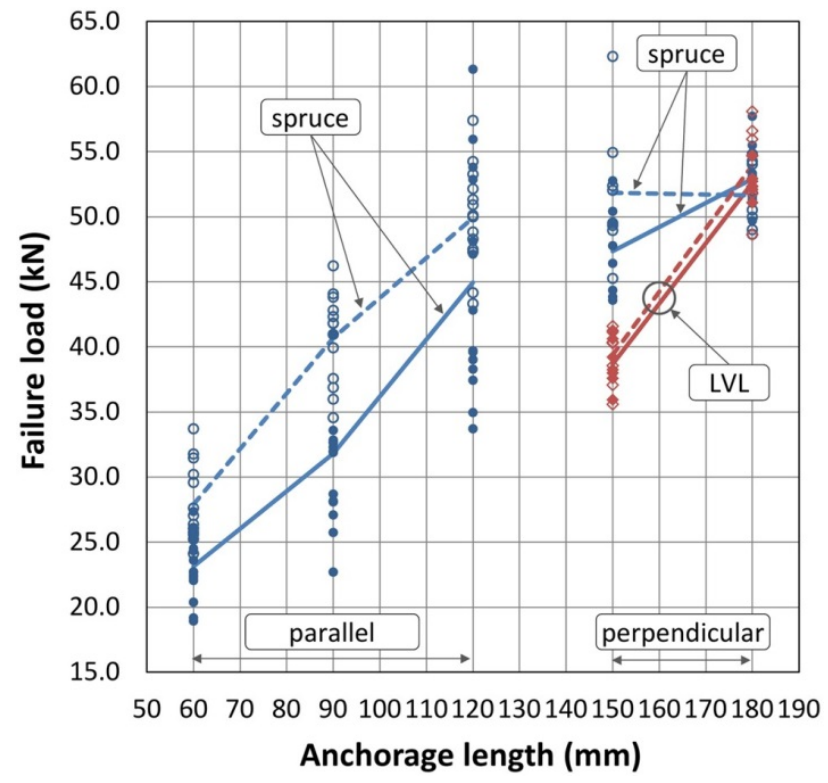

Fig. 6 Experimental results and average values (joined by lines) for cylindrical holes (solid lines) and test pieces with countersinking (dashed lines)

The tests performed are shown in Fig. 4, options IIa to IId, and in Fig. 7. The first three options were created using articulated bits, while IId (Fig. 4) was executed using an eccentric bit. As may be seen in the image, option IIb (Fig. 4) uses a bulb that does not coincide exactly with the end of the hole, and it was created using one of the prototype bits that were designed.

The four solutions were studied experimentally and compared with cylindrical holes in spruce glulam test pieces with joints created parallel to the fibre. Figure 8 shows the results and average values obtained experimentally for glued lengths from 60 to $120 \mathrm{~mm}$. Improvements were obtained with solutions IIa and IId (in average values) of $31.6 \%$ and $26.0 \%$, respectively, for a glued length of $60 \mathrm{~mm}$. This improvement falls to approximately $17-19 \%$ for a glued length of $90 \mathrm{~mm}$, and it is practically zero for a glued length of $120 \mathrm{~mm}$. Solution IIb gave less improvement than the previous versions for lengths of $60 \mathrm{~mm}$ and $90 \mathrm{~mm}$. Solution IIc produced no significant improvements in any of the lengths tested, and it showed less resistance for joints measuring $120 \mathrm{~mm}$. 
The difference in behaviour may be explained by observing the failure modes in the different test pieces. In short lengths, the bulb is extracted entirely, without breaking, dragging out the upper block of timber (Fig. 9, top). However, in longer glued lengths, failure of the bulb occurs due to tangential stresses, leading to shearing failure of the joint in a surface that is closer to the initial cylindrical hole (Fig. 9, bottom).

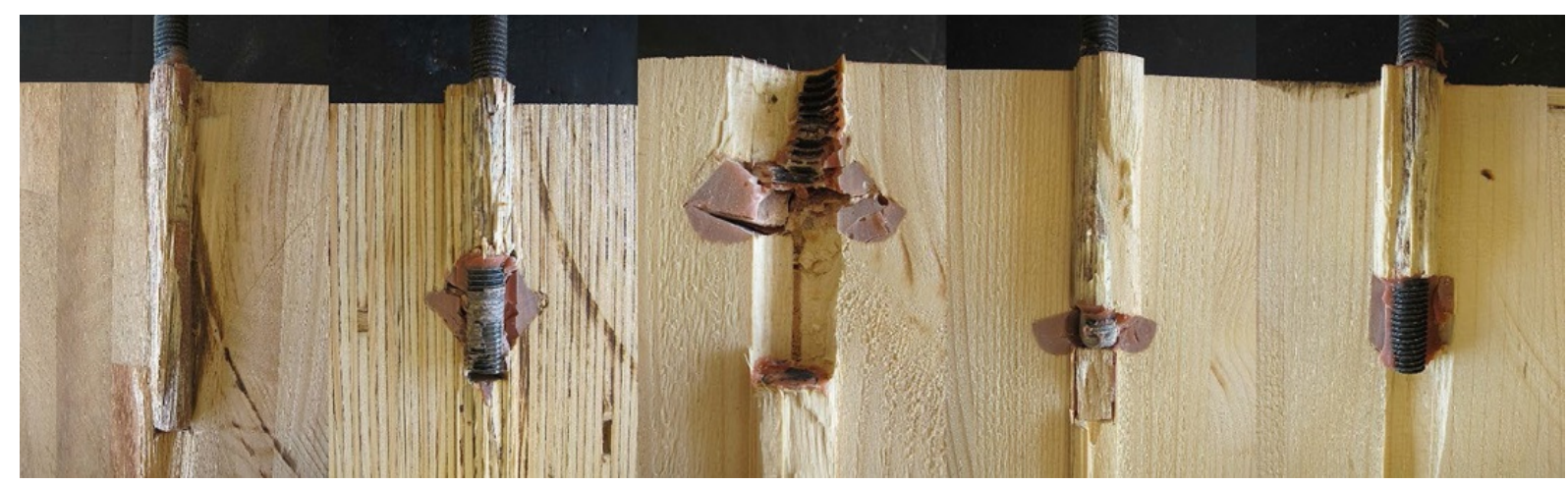

Fig. 7 Cylindrical anchorage (type o-Fig. 4) and different configurations of bulbs, which were tested (type IIa, IIb, IIc and IId in Fig. 4, respectively)

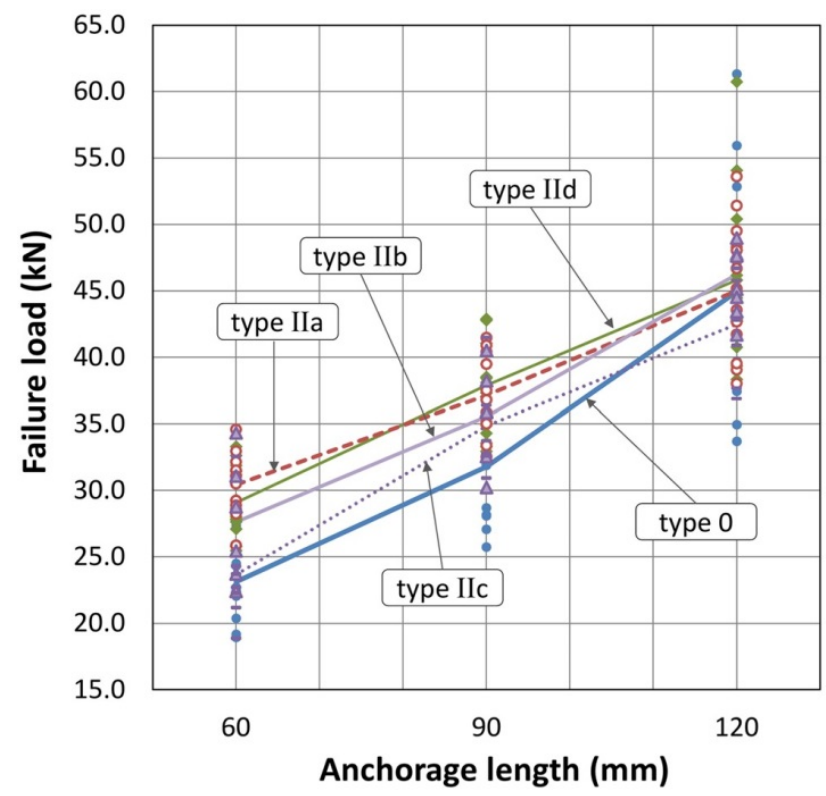

Fig. 8 Experimental results and average values (joined by lines) for joints made parallel to the fibre in spruce glulam with different types of bulb

The tests were performed with the same geometrical characteristics in joints made perpendicular to the fibre. Solution IIc was not tested in this case, as it had performed poorly in test pieces parallel to the fibre. Although the efficacy of the bulbs also fell with the anchorage length, in joints made perpendicular to the fibre, the difference in behaviour between the different lengths was not as great as it was in joints made parallel to the fibre. The average improvements in strength values in comparison with type-o joints amounted to 20.6 to $34.1 \%, 16.7$ to $19.6 \%$ and 8.2 to $14.2 \%$ for lengths of $60 \mathrm{~mm}, 90 \mathrm{~mm}$ and $120 \mathrm{~mm}$, respectively (Fig. 10). In this case, the failure mode showed crushing of the wood around the bulb (Fig. 11). 
In view of the above results, an experimental campaign was conducted to evaluate the effect of the average density of timber species on the behaviour of joints with bulbs. This study centred on the behaviour of bulbs in solutions IIa and IId, given that these had shown the best behaviour in previous results. Laminated wood from different tree species was used: chestnut, oak and eucalyptus, with average densities of around $590 \mathrm{~kg} / \mathrm{m}_{3}, 690 \mathrm{~kg} / \mathrm{m}_{3}$ and $790 \mathrm{~kg} / \mathrm{m}_{3}$, respectively. Tests were also performed with LVL test pieces (with an average density of around $530 \mathrm{~kg} / \mathrm{m} 3$ ).

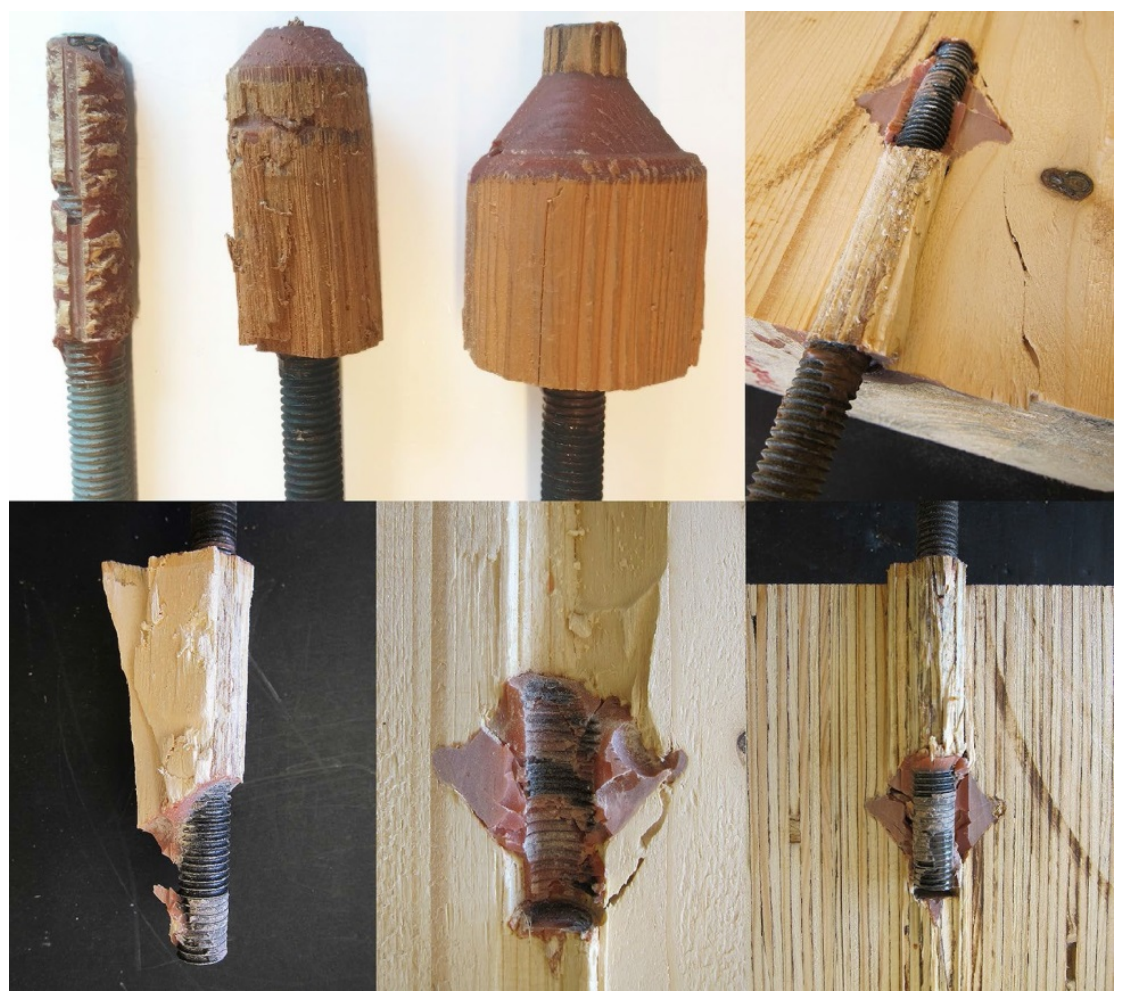

Fig. 9 Top: extraction of the bulb, dragging out a block of timber, the predominant failure mode in test pieces with shorter anchorages. Bottom: breakage of the adhesive bulb, the predominant failure mode in test pieces with medium length anchorages

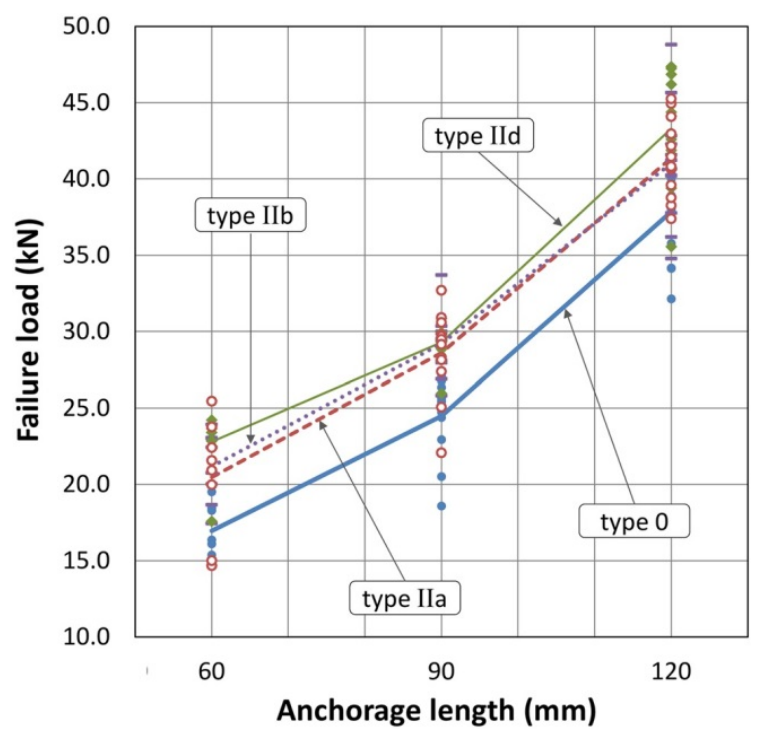

Fig. 10 Experimental results (average values) for joints made perpendicular to the fibre in spruce glulam with different types of bulb 


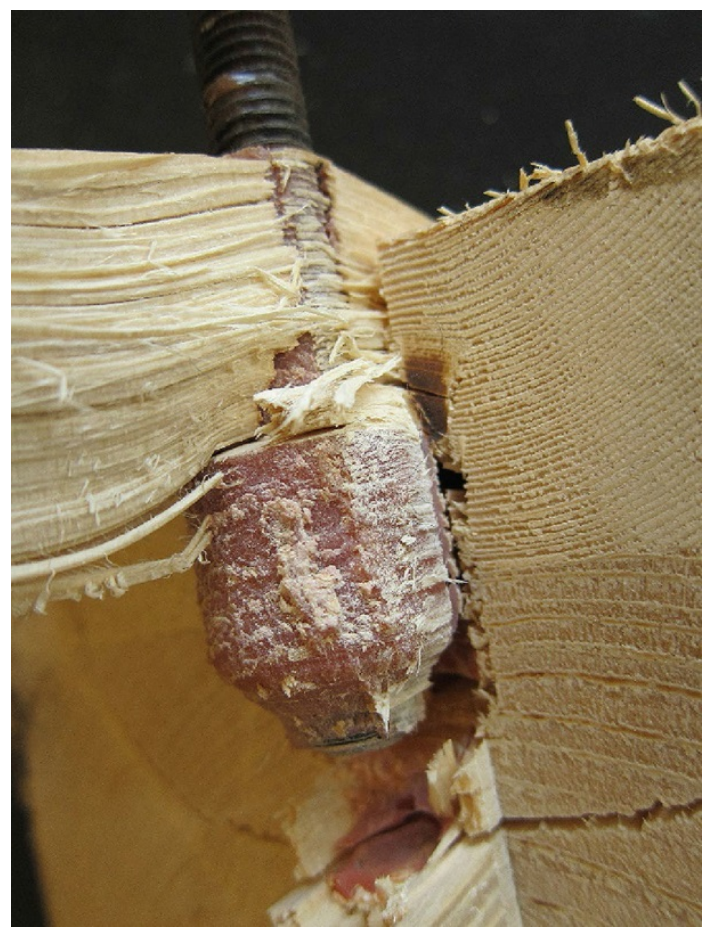

Fig. 11 Extraction of the bulb and crushing of the wood, the predominant failure mode in test pieces with an anchorage perpendicular to the fibre

Glued joints parallel to the fibre in the above-mentioned laminated woods were found to behave in a similar way to those made of spruce glulam. Nevertheless, the standard deviation of the results was generally greater than it was for spruce glulam and LVL. The joints with a bulb showed higher degrees of improvement in short anchorages, and improvement was reduced as the length of the joint increased. The bulb was less effective in the longer joints or even had strength values lower than those of joints made with a cylindrical hole (Fig. 12a). This is because the higher density of the wood made it more resistant against shearing and compression perpendicular to the fibre, so that more failures occurred due to failure of the bulb (Fig. 9, bottom).

In the tests performed in LVL, slenderness had less influence on strength than was the case for laminated wood, showing behaviour that was more similar to those of the tests in spruce glulam with joints perpendicular to the fibre, although with improvement percentages that are higher in comparison with cylindrical holes (Fig. 12b). The failure mode was similar to that of holes parallel to the fibre in spruce glulam, with extraction of the block of timber in short joints and breakage of the bulb in longer ones (Fig. 9).

Improvements in the average strength with solution IIa were higher than $60 \%$ in the shortest glued length and somewhat lower than 30\% in the longest length.

When the experimental results of this solution are com- pared with those of the previous type (Type I), in joints with a slenderness of 5.0, bulbs give rise to an increase in joint strength of $4 \%$ and $9 \%$ for types IId and IIa, respectively. However, for a slenderness from 7.5 to 10.0, type I solution is in all cases 7-10\% stronger than those with bulbs. Type IIb and IIc solutions are inferior to those with countersinking in all cases. 


\subsection{Experimental analysis of joints with multiple bulbs along the contact surface}

In spite of the enormous efficacy displayed by the solution with bulbs in shorter anchorages, the failure mode observed in the adhesive restricts its application in longer anchorages. Although some additional tests were performed using other highly resistant structural adhesives, the geometrical configuration of the bulbs always led to the same type of failure in long joints. An alternative was therefore proposed, which made it possible to improve the behaviour of longer joints, based on the same articulated bit system studied in the previous section.

The proposed solution in this case consisted of making a set of bulbs (multiple bulbs) or widenings along the whole length of the anchorage, to distribute the shear force along it and thereby limit its failure. The maximum diameter of the widening was also restricted, to obtain a thinner layer of adhesive in which transversal shear forces were reduced.

A first alternative was proposed (solution IIIa in Fig. 4) consisting of cylindrical widenings made with an eccentric bit. The resulting shape in the adhesive layers gave rise to large concentrations of stress in the glueline that caused the bulb to break at low loads, so that this option was immediately rejected.
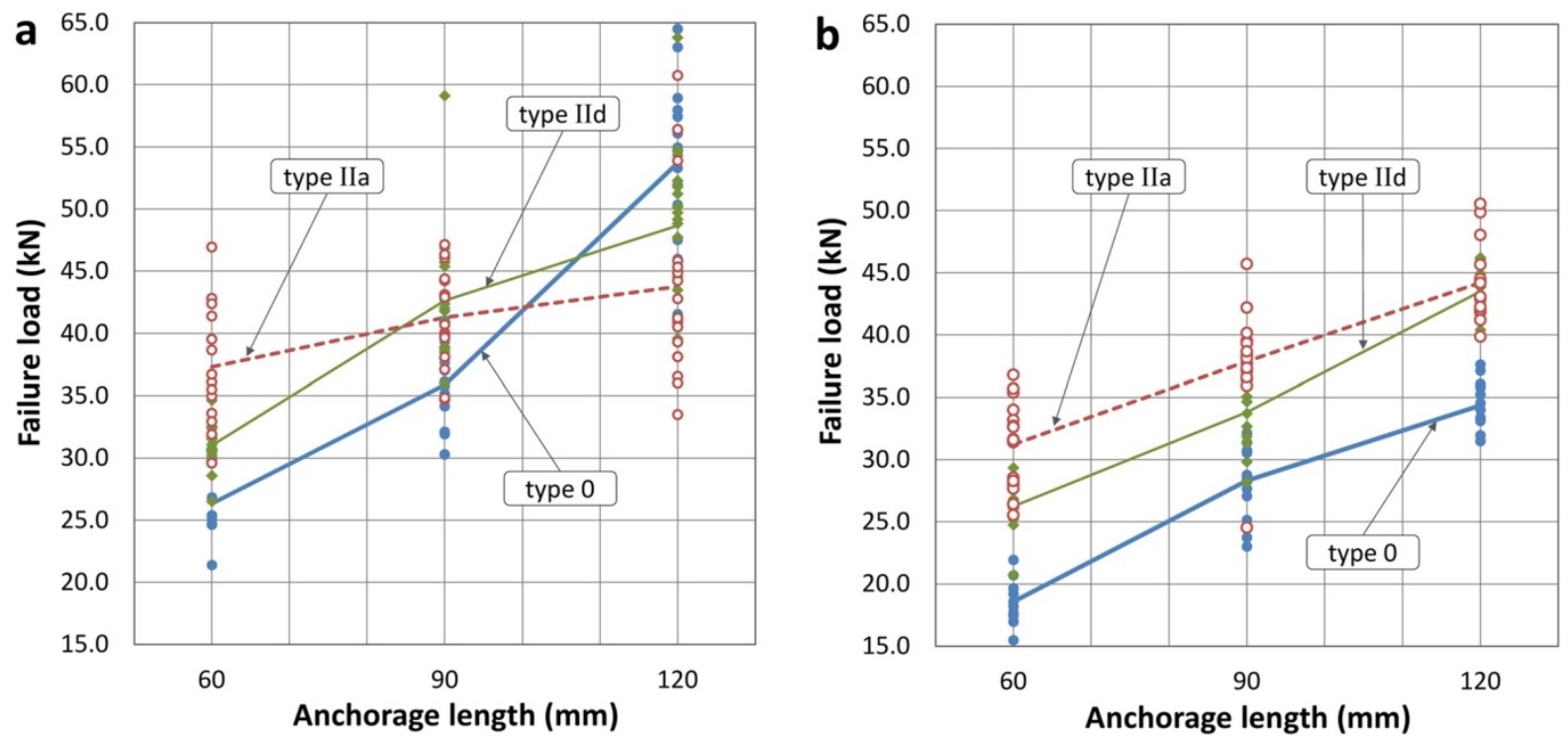

Fig. 12 Experimental results and average values (joined by lines) for joints made parallel to the fibre in chestnut glulam (a) and LVL (b) with different types of bulb

Experimental analysis centred on proposals IIIb and IIIc (Fig. 4), which were executed using the same articulated rods designed for the simple bulbs. By placing a stop in the end of the bit it is possible to execute widenings simply at different depths of the cylindrical pre-hole (Estévez-Cimadevila et al. 2013). In solution IIIb, the opening of the bit was restricted in all of the widenings, giving rise to smaller diameter bulbs; and in solution IIIc a single large bulb was created of the same diameter as in solution IIa, in the interior end. These widenings may be made by using the tool with a conventional drill. Tests were performed parallel to the fibre in laminated spruce glulam and chestnut glulam. The glued lengths in this case varied from $90 \mathrm{~mm}$ to $150 \mathrm{~mm}$ (slenderness ratios of $7.5^{-12.5}$ ), given that the aim was to validate their behaviour for longer glued lengths. 
The experimental results are shown in Fig. 13, comparing the results with those in cylindrical anchorages and in those with a single bulb. The improvements ranged from 40 to $66 \%$ for solution IIIb, for joints made of spruce glulam as well as chestnut glulam, and they were even maintained for longer lengths (with a slenderness ratio of 12.5).

There was less improvement in solution IIIc, between 24 and 42\%, in spite of the fact that the theoretical volume due to the bulb is greater in this solution than it is in IIIb (Fig. 14a). This is because the larger diameter bulb at the end of solution IIIc sometimes caused the same type of failure as was observed in the test pieces with a single bulb (Fig. 14b). No case of adhesive failure occurred in solution IIIb test pieces, obtaining superior joint performance (Fig. 14c).

As this solution makes it possible to increase the timber surface involved in failure, it therefore increases the strength of the joint without the need to use larger diameter rods to make it possible to design for ductile joint failure. On the other hand, increasing the contact surface and using thicker layers of adhesive along the whole joint is not a good solution, as the majority of adhesives is designed to work in thin layers. Some authors have experimentally proven the cohesive failure of adhesive when it is used in thick layers (Franke and Franke 2018).

Compared to the previous solutions, type IIIb joints fail at loads from 31 to $42 \%$ higher than the best performing ones in spruce with bulbs. This improvement was from 39.8 to $54.6 \%$ for chestnut test pieces, for a slenderness of 7.5 and 10.0, respectively. Of the type I test pieces, the type IIIb solution gave an increase in failure loads of $21.9 \%$ and $28.1 \%$, for a slenderness of 7.5 and 10.0 , respectively.

\subsection{Design recommendations for the use of improved joints made with GiR}

High strength GiR joint design may make it necessary to use large diameters or long anchorage lengths. On the other hand, large diameter rods require large distances to the edge to prevent failure due to splitting of the wood. Increasing the anchorage length is also restricted, as for a certain rod diameter there is a slenderness over which increasing the length hardly increases the load-bearing capacity of joints. This limiting slenderness value varies with the type of wood used.
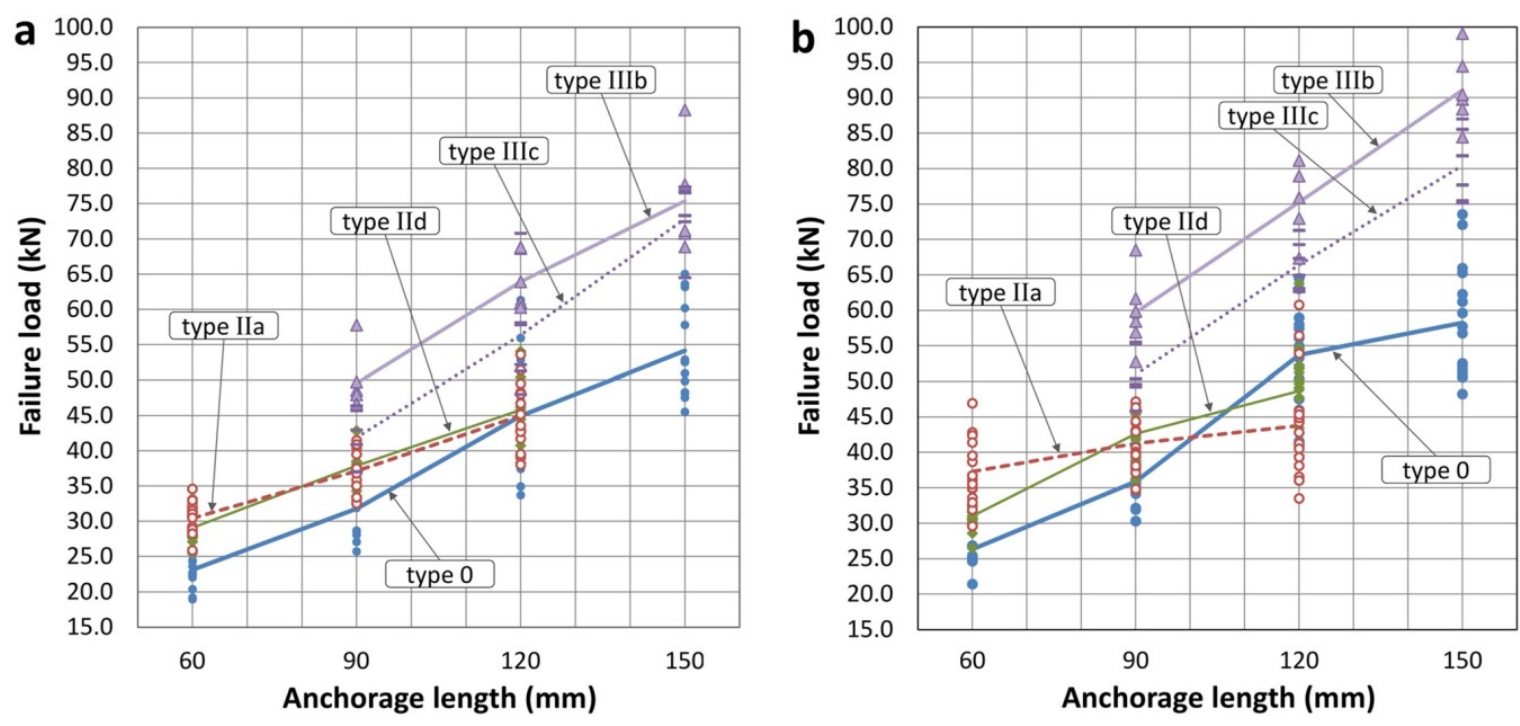

Fig. 13 Experimental results and average values (joined by lines) for joints parallel to the fibre in spruce glulam (a) and chestnut glulam (b) with different types of bulb 


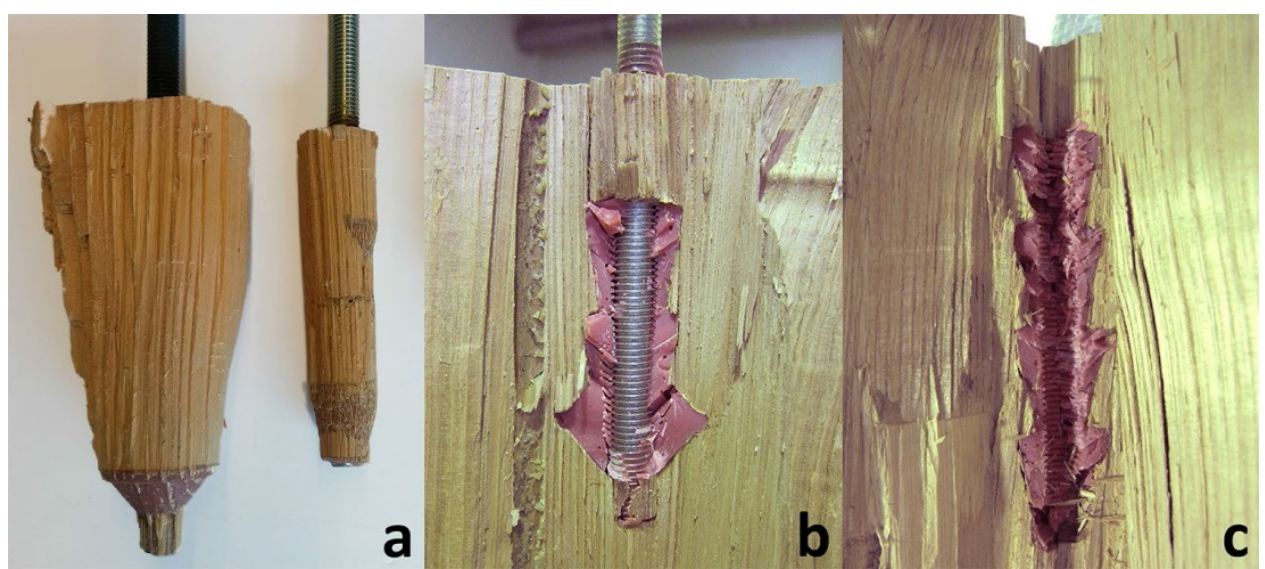

Fig. 14 Failure modes in test pieces with multiple bulbs. a Extraction of the joint in solutions IIIc and IIIb. b Type IIIc test piece open following failure. c Type IIIb test piece open following failure.

Although joint strength may be increased by using hardwood species instead of spruce, this conditions the design of the whole structure. Additionally, the increase in structural self-weight arising from the use of the former type of wood may exceed the increased load-bearing capacity of the joints.

The use of some of the improvement systems described in Sect. 3 may increase the strength of joints without the need to increase rod diameter or glued-in length. Using narrower diameter rods makes it possible to design for ductile joint failure. This occurs when a design aims for failure to arise due to rod tension before shear failure of the wood. In any case, certain minimum separations and distances to the edge are required to prevent other types of premature brittle failure of the wood (such as tensile failures or splitting).

For joints with a slenderness of 5.0, type II holes improve load-bearing capacity in comparison with traditional GiR. They may attain $32-68 \%$ greater capacity, depending on the type of hole drilled, fibre direction and the type of wood used. For higher slenderness joints (from 7.5 to 15.0) the increase in load-bearing capacity achieved with type IIIb joints compared to type o ones may range from 39 to $66 \%$, depending on the wood used and the slenderness of the joint.

\section{Conclusion}

This paper describes a range of proposals to improve the behaviour of joints made using GiR, including variations in the conventional solution that is based on the use of cylindrical rods and holes. The solutions found in the literature may be classified into four large groups: hooped solutions, hybrid joints, solutions based on modified rod shapes and solutions based on modified hole shapes. Some proposals have been studied analytically and/or experimentally, achieving improvements in load-bearing that are generally limited.

Additionally, a broad experimental study is described, in which three enhancement systems based on modifying the shape of the hole were experimentally analysed. The systems were tested in different species of timber, covering a broad range of densities and varying the length of the anchorage as well as the direction of the holes respecting the direction of the fibre. 
The enhancement system based on the use of external countersinking achieved increases in the strength of the joint of around 30\% for joints in spruce glulam with slenderness ratios from 5 to 10. The system was found to be hardly effective in anchorages that were perpendicular to the fibre in spruce glulam and LVL for slenderness ratios of 12.5 and 15 .

The enhancement system based on the use of single interior bulbs achieved significant increases in strength (greater than 30\%) in short glued lengths (with a slender- ness ratio of 5) in joints parallel to the fibre. This system becomes less effective as the slenderness ratio of the joint increases. Increasing the average density of the wood used also caused the efficacy of the system to decline. In joints perpendicular to the fibre, the slenderness ratio of the joint had less effect on its effectiveness.

The system based on the use of multiple bulbs in joints parallel to the fibre achieved major improvements in their load-bearing capacity, of up to $60 \%$ in joints with a slenderness ratio of up to 12.5 , regardless of the aver- age density of the wood used. This increase in strength is higher than the increases reported in the literature for other enhancement systems.

\section{References}

Aicher S, Hezel J, Stapf G (2012) Mechanical and glued joints of ultrahigh efficiency. In: Proceedings of world conference of timber engineering, Auckland

Batchelar ML, McIntosh KA (1998) Structural joints in glulam. In: Proceedings of $5^{\text {th }}$ world conference on timber engineering, Montreux, pp 289-296

Broughton JG, Hutchinson AR (2001) Pull-out behaviour of steel rods bonded into timber. Mater Struct 236:100-109

Buchanan A, Moss P (1999) Design of epoxied steel rods in glulam timber. In: Proceedings of Pacific timber engineering confer- ence, vol 3, Rotoura, pp 286-293

Buchanan AH, Moss PJ, Eistetter S (2000) Cement grouted steel bars in glulam. In: Proceedings of world conference of timber engineering, British Columbia

BVD-Bertsche (1998) Zulassung Z-9.1-233 BVD-Ankerdübel- Verbindung (Approval Z-9.1-233: BVD anchor bolt connec- tion) Holder: Dipl.-Ing. P. Bertsche. German building approval Deng JX, Moss PJ, Buchanan AH (1998) Glued bolts in glulam-an analysis of stress distribution. In: Proceedings of $5^{\text {th }}$ world conference on timber engineering, Montreux, pp 206-213

Estévez-Cimadevila J, Otero Chans D, Martín Gutiérrez E, Vázquez Rodríguez J (2012) New anchoring system with adhesive bulbs for steel rod joints in wood. Constr Build Mater 30:583-589. https://doi.org/10.1016/j.conbuildmat.2011.12.052

Estévez-Cimadevila J, Otero-Chans D, Martín-Gutiérrez E (2013) Adhesive multi-bulbs: a novel anchoring system using threaded steel rods glued into wood. Constr Build Mater 48:131-136. https://doi.org/10.1016/j.conbuildmat.2013.06.079

Franke S, Franke B (2018) Fundamentals and recent strength results of connections in modern hardwood timber structures. Wood Mater Sci Eng. https://doi.org/10.1080/17480272.2018.1526822

Gattesco N, Gubana A (2001) Experimental tests on glued joints under axial forces and bending moments. In: Proceedings of joints in timber structures, international RILEM symposium, Stuttgart, pp 353-362

Gaunt D (1999) Joints in glulam using groups of epoxy-grouted steel bars. Inst Prof Eng N Z Trans 26:34-37 Grunwald C, Vallée T, Fecht S, Bletz-Mühldorfer O, Diehl F, Bathon L, Myslicki S, Scholz R, Walther F (2019a) Rods glued in engineered hardwood products part I: experimental results under quasi-static loading. Int $J$ Adhes Adhes 90:163-181. https://doi.org/10.1016/j.ijadhadh.2018.05.003 
Grunwald C, Vallée T, Fecht S, Bletz-Mühldorfer O, Diehl F, Bathon L, Walther F, Scholz R, Myslicki S (2019b) Rods glued in engineered hardwood products part II: numerical modelling and capacity prediction. Int J Adhes Adhes 90:182-198. https://doi.org/10.1016/j.ijadhadh.2018.05.004

Harvey K, Ansell MP (2000) Improved timber connections using bonded-in GFRP rods. In: Proceedings of world conference of timber engineering, British Columbia Hunger F, Stepinac M, Rajčić V, van de Kuilen JWG (2016) Pull-compression tests on glued-in metric thread rods parallel to grain in glulam and laminated veneer lumber of different timber species. Eur J Wood Prod 74:379-391.

Hunger F, Stepinac M, Rajčić V, van de Kuilen JWG (2016) Pull-compression tests on glued-in metric thread rods parallel to grain in glulam and laminated veneer lumber of different timber species. Eur J Wood Prod 74:379-391. https://doi.org/10.1007/s00107-015-1001-2

Korin U, Buchanan AH, Moss PJ (1999) Effect of bar arrangement on tensile strength of epoxied end bolts in glulam. In: Proceedings of Pacific timber engineering conference, vol 2, Rotoura, pp 217-224

Martín E, Estévez J, Otero D (2013) Influence of geometric and mechanical parameters on stress states caused by threaded rods glued in wood. Eur J Wood Prod 71:259-266. https://doi.org/10.1007/s00107-013-0678-3

Muciaccia G (2019) An experimental approach to determine pull-out strength of single and multiple axially loaded steel rods bonded in glulam parallel to the grain. Wood Mater Sci Eng 14:88-98. https://doi.org/10.1080/17480272.2017.1404491

Otero-Chans D, Estévez-Cimadevila J, Martín-Gutiérrez E (2008) Glued joints in hardwood timber. Int J Adhes Adhes 28:457-463. https://doi.org/10.1016/j.ijadhadh.2008.04.008

Otero-Chans D, Estévez-Cimadevila J, Martín-Gutiérrez E (2010) Model for predicting the axial strength of joints made with glued-in rods in sawn timber. Constr Build Mater 24:1773-1778. https://doi.org/10.1016/j.conbuildmat.2010.02.010

Otero-Chans D, Estévez-Cimadevila J, Martín-Gutiérrez E (2013) Withdrawal strength of threaded steel rods glued with epoxy in wood. Int $J$ Adhes Adhes 44:115-121. https://doi.org/10.1016/j.ijadhadh.2013.02.008

Otero-Chans D, Estévez-Cimadevila J, Martín-Gutiérrez E (2014) Orientation of bars glued on glued laminated products: parallel vs. perpendicular. Compos Part B Eng 62:97-103. https://doi.org/10.1016/j.compositesb.2014.02.028

Riberholt H (1986) Glued bolts in glulam. Technical report. Technical University of Denmark, Serie R, n210. ISBN 87-87336-63-4

Riberholt H, Spøer P (1983) Indlimede bolte til indfætning af vingerne på nibe-mølle B. (In-glued rods for the mill wingblade on Nibemolle-B) (in Danish).Technical report. Technical University of Denmark, Serie R, n167. ISSN 0108-0768

Steiger R, Gehri E, Widmann R (2004) Glued-in steel rods: A design approach for axially loaded single rods set parallel to the grain. In: Proceedings of the CIB-W18, meeting 37, Edinburg, Paper 37-7-8

Steiger R, Serrano E, Stepinac M, Rajĉić V, O’Neill C, McPolin D, Widmann R (2015) Strengthening of timber structures with glued- in rods. Constr Build Mater 97:90-105. https://doi.org/10.1016/j.conbuildmat.2015.03.097

Tlustochowicz G, Serrano E, Steiger R (2011) State-of-the-art review on timber connections with glued-in steel rods. Mater Struct 44:997-1020. https://doi.org/10.1617/s11527-010-9682-9

Uhre Pedersen M, Clorius CO, Damkilde L, Hoffmeyer P (1999) Strength of glued-in bolts after fullscale loading. J Per- form Constr Facil 13:107-113. https ://doi.org/10.1061/ (ASCE)o8873828(1999)13:3(107)

Vallée T, Tannert T, Fecht S (2017) Adhesively bonded connections in the context of timber engineering-a review. J Adhes 93:257-287. https://doi.org/10.1080/00218464.2015.1071255

Wernersson H, Gustafsson PJ (1996) A mixed-mode model for analysis of brittle and ductile glued joints. In: International wood engineer- ing conference, vol 4, Louisiana, pp 481-487

Yeboah D, Taylor S, McPolin D (2016) Experimental study of inter- facial stress distribution of bonded-in BFRP rod glulam joints using fibre optic sensors (FOS). Structures 8:53-62. https://doi.org/10.1016/j.istruc.2016.08.006 